\title{
FLOWERING IN PISUM: MULTIPLE ALLELES AT THE If LOCUS
}

\author{
I. C. MURFET \\ Botany Department, University of Tasmania, Hobart, Australia
}

Received 19.xi.74

\begin{abstract}
Summary
Two further alleles $l f^{a}$ and $L f d$ are proposed for the flowering gene $L f$. The dominance order is $L f d>L f>l f>l f a$, with ability to delay flowering descending in that order. Homozygous $l f^{a}$ plants can flower as early as node 5 or 6 but generalised statements regarding the flowering node for these alleles are avoided since the position depends on the status of the other major flowering loci, the background for various quantitative systems and the environmental conditions. In the present crosses heterozygotes of $l f^{a}$ with the other alleles were always distinguishable from the $l^{a}$ homozygotes and segregation was therefore distinct even in long days. Parental lines 60 (lf E Sn hr) and 7 ( $l f a E S n h r$ ) flowered less than four nodes apart but dominance of $l f$ over $l f^{a}$ was 0.69 and strong canalisation of development in this early region allowed classic Mendelian analysis of the data. A relatively strong polygenic system contributed to within-class variation of $l f^{a}$ and $l f$ plants. The degree of dominance of $L f$ over $l f^{a}$ varied with the photoperiod and the background of internode-length genes. $L f^{d} L f$ heterozygotes were not clearly distinguishable from either homozygote. The results of graft studies are in agreement with the proposal that the $L f$ alleles determine sensitivity of the apex to the flowering hormones. Type lines are appointed for the four alleles.
\end{abstract}

\section{INTRODUCTION}

UNDER field conditions flowering often shows continuous variation and many workers using these conditions have analysed their data by the methods of quantitative genetics (Clay, 1935; Rowlands, 1964; Watts et al., 1970; Snoad and Arthur, 1973a, b). These workers generally conclude that flowering node and flowering time are under the control of simple, additive, polygenic systems with dominance of little importance but Rowlands also found evidence of a major gene or " effective factor" (possibly $S n$ ) which delayed flowering and whose effect was increased in short days. Distinct segregations can occur under the daylength conditions operating in the field, and this paper contains examples, but the likelihood of obtaining a discrete segregation is generally improved by choosing environmental conditions which magnify the effect of a particular gene or gene combination. This technique was used by Barber (1959) and Marx $(1968,1969)$ and has been used in the present studies to attempt a Mendelian analysis of flowering.

The first paper in this series showed how six phenotypic classes could be recognised in a diverse group of pea varieties by the use of flowering node and flowering time data obtained under controlled photoperiod conditions (Murfet, 1971a). Each class was defined in relation to the behaviour of a standard variety. Four of these classes namely ED (early developing), EI (early initiating), L (late) and LHR (late high response) have now been investigated and four major genes-Lf $\left(=S_{1}\right), E, S n\left(=S_{2}\right)$ and $H r$-have been found to determine between-class variation and to some 
extent within-class variation, but there is also evidence of polygenic systems which in contrast seem to contribute mostly to within-class variation but occasionally to between-class variation as in the case of the penetrance modifiers of $S n$ (Murfet, 1971b, 1973b). Genotype lf e $s n h r$ is ED; it is early (flowers about node 10) and day-neutral. Addition of $S n$ creates an L-type

TABLE 1

Distribution of node of first initiated flower for parents, $F_{1}, F_{2}$ and $F_{3}$ of cross 7 (lf ${ }^{\text {a }} \mathrm{E} \mathrm{Sn} \mathrm{hr}$ ) $\times 60$ (lf $\mathrm{E} \mathrm{Sn} \mathrm{hr}$ ). $F_{3}$ families of 12 plants were used to genotype the small $F_{2}$ and check the critical $8 / 9$ region in the large $F_{2}$. Photoperiod 8 hours

\begin{tabular}{|c|c|c|c|c|c|c|c|c|c|c|c|c|}
\hline \multirow[b]{2}{*}{ Generation } & \multirow[b]{2}{*}{ Genotype } & \multicolumn{11}{|c|}{ Node of first flower } \\
\hline & & 6 & 7 & & 8 & 9 & 10 & 11 & 12 & 13 & 14 & 15 \\
\hline Line 7 & $l f^{a} l f^{a}$ & 1 & 10 & & 1 & - & - & 一 & - & - & - & 一 \\
\hline Line 60 & lf lf & - & 一 & & - & - & 10 & 9 & 3 & - & - & - \\
\hline $\mathrm{F}_{1}$ & lf $l^{a}$ & - & - & & - & - & 5 & 9 & - & - & - & - \\
\hline small $F_{2} *$ & - & 1 & 9 & & 9 & 2 & 8 & 28 & 8 & - & - & - \\
\hline $\mathrm{F}_{2} \uparrow$ & $l f^{a} l f^{a}$ & 1 & 9 & & 9 & - & - & - & - & - & - & - \\
\hline $\mathrm{F}_{2} \uparrow$ & lf $l^{a}{ }^{a}$ & - & - & & - & 2 & 8 & 22 & 4 & - & - & - \\
\hline $\mathrm{F}_{2} \dagger$ & lf lf & 一 & 一 & & - & - & - & 6 & 4 & - & - & 一 \\
\hline$F_{3}$ & $l f^{a} l f^{a}$ & 19 & 178 & $\downarrow$ & 28 & 1 & - & - & - & - & - & - \\
\hline$F_{3}$ & - & 5 & 70 & & 38 & 36 & 133 & 90 & 43 & 12 & 3 & - \\
\hline$F_{3}$ & lf lf & - & - & & - & 1 & 27 & 37 & 27 & 13 & 1 & 1 \\
\hline large $F_{2}{ }^{*}$ & $-\cdots$ & - & 27 & & 24 & 13 & 72 & 69 & 16 & 3 & - & - \\
\hline$F_{3}$ & $l f^{a} l f^{a}$ & 1 & 74 & & 21 & & $m$ & - & - & - & - & - \\
\hline$F_{3}$ & -- & 2 & 30 & & 5 & $\begin{array}{r}v \\
24\end{array}$ & 62 & 6 & - & - & - & - \\
\hline $\mathrm{F}_{2}+\mathrm{F}_{3}+$ & -- & 8 & 136 & & 76 & 75 & 275 & 193 & 67 & 15 & 3 & - \\
\hline
\end{tabular}

* All $\mathrm{F}_{2}$ plants flowering at node 9 segregated in $\mathrm{F}_{3}$.

$\dagger$ Degree of dominance of $l f$ over $l f^{a}=0.69$.

$¥$ Total lfllfa seg. $628 / 220\left(\chi_{1}^{2} 0 \cdot 40\right)$, cutting between nodes 8 and 9 .

which is quantitatively delayed (5-15) nodes) by short days but which is also a few nodes later in long days than the standard ED line if the seed is buried. Gene $E$ is epistatic to $S n$ in terms of flowering node and genotype If $E S n h r$ is EI; the node of first initiated flower is early and day-neutral but the flowering time is delayed in short days as a result of retarded development or abortion of the lower flower buds. $L f$ is epistatic to $E$ and genotype $L f E S n h r$ is again L-type. Genes $H r$ and $S n$ interact strongly and genotype lf e Sn $\mathrm{Hr}$ is LHR; it flowers with the L plants in long days but is very extensively delayed (25-50 nodes) in warm short day conditions. Genotypes $L f e s n h r$, lf $E s n h r$ and lf e sn $H r$ are basically ED but $H r$ confers 


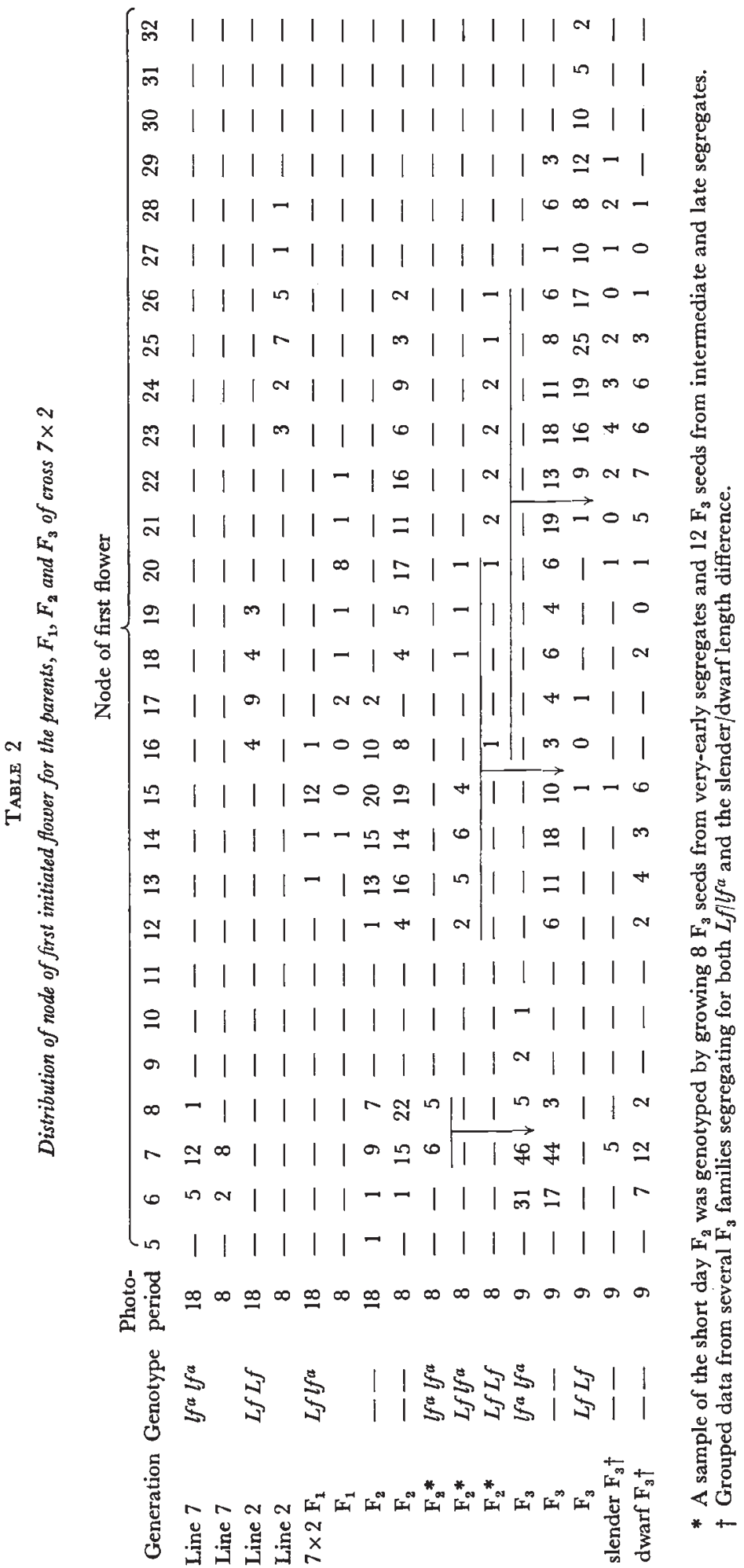


EI tendencies (Murfet, 1973a) and $L f$ raises the flowering node particularly where assisted by a system of polygenic modifiers (Murfet, unpublished). In the present work the two remaining phenotypic classes, namely the extreme types VEI (very early initiating) and VL (very late) are brought into the genetic analysis. VEI plants are some three to four nodes earlier than the standard EI line and VL plants show the extensive flowering delay in short days characteristic of LHR plants but are also five to eight nodes later in long days than the standard L and LHR lines.

The findings from this series differ widely from those in the quantitative papers in that dominance and interaction are very marked and substantial transgressive segregation was reported in some crosses (e.g. Murfet, 1971b,

TABLE 3

Distribution of node of first initiated flower for the parents, $F_{1}$ and $F_{2}$ of cross 24 (a Lf e Sn hr m) $\times 16$ (A Lf ${ }^{\mathrm{d}} \mathrm{E} \mathrm{Sn}$ $\mathrm{Hr}$ M). Photoperiod 18 hours

\begin{tabular}{|c|c|c|c|c|c|c|c|c|c|c|c|c|c|c|c|}
\hline \multirow[b]{2}{*}{ Generation } & \multicolumn{12}{|c|}{ Node of first flower } & \multirow[b]{2}{*}{$\bar{x}$} & \multirow[b]{2}{*}{ S.E. } & \multirow[b]{2}{*}{$n$} \\
\hline & Genotype & 15 & 16 & 17 & 18 & 19 & 20 & 21 & 22 & 23 & 24 & 25 & & & \\
\hline Line 24 & $L f$ & - & 9 & 2 & 1 & - & - & 一 & - & - & - & - & - & - & 一 \\
\hline Line 16 & $L f^{a}$ & - & - & - & - & 一 & - & - & 1 & 1 & 8 & 1 & - & - & 一 \\
\hline$F_{1}$ & $L f^{a} L f$ & - & - & - & - & 1 & 2 & 6 & 6 & 4 & - & - & - & - & - \\
\hline$F_{2}$ & -- & 2 & 12 & 12 & 22 & 34 & 21 & 19 & 10 & 5 & 9 & 3 & - & - & - \\
\hline $\mathbf{F}_{2}$ & $A M$ & - & 1 & 3 & 4 & 19 & 17 & 15 & 8 & 5 & 9 & 2 & $20 \cdot 6$ & 0.2 & 83 \\
\hline$F_{2}$ & $A m$ & 1 & 1 & 1 & 11 & 13 & 3 & 2 & - & - & - & 1 & $18 \cdot 8$ & $0 \cdot 3$ & 33 \\
\hline$F_{2}$ & $a M$ & - & 6 & 4 & 5 & 2 & - & 2 & 1 & - & - & - & $17 \cdot 8$ & 0.4 & 20 \\
\hline$F_{2}$ & $a m$ & 1 & 4 & 4 & 2 & - & 1 & - & 1 & - & - & - & $17 \cdot 3$ & 0.5 & 13 \\
\hline
\end{tabular}

The strong linkage of genes $L f$ and $H r$ with the pigment genes $A$ and $M$ respectively allows partial recognition of the effects of the flowering genes in this continuous $\mathrm{F}_{2}$.

Differences: $a m-A m 1 \cdot 49, t=2 \cdot 50^{*} ; a M-A M 2 \cdot 83, t=6 \cdot 11 * * *$

a $m-a M 0.50, t=0.75 ; A m-A M 1 \cdot 84, t=4 \cdot 67^{* * * *}$.

table 8). However, the different results are possibly reconcilable on the grounds that the relative contribution of each gene or gene system and properties such as dominance, interaction and transgression are all dependent on the genetic and environmental circumstances operating. Whether a gene shows clear-cut segregation or is obscured in a quantitative system is therefore a function of circumstance.

\section{Materials AND Methods}

Five of the varieties used here have already been investigated (Murfet, 1971b). They are lines 60, lf E Sn hr, EI; 22, lf E/e sn hr, ED; 2, Lf E Sn hr, L; 24, Lf e Sn hr, L; and 63, lf e Sn Hr, LHR. Lines 60, 24 and 63 are the standard varieties for their respective classes. Line 22 is a bulk selection from cultivar Massey with heterogeneity at the $E$ locus. The two new varieties brought into the crossing programme are line 7 (Lamm L7, Nilsson L54, Vilmorin's "Acacia ") phenotype VEI and line 16 (believed to be Wellensiek's "Dominant" line) phenotype VL.

The crosses reported are $7 \times 60,7 \times 2,7 \times 16$ and $24 \times 16$. Data on parents, $F_{1}$ and reference varieties in tables 1-4 come from plants grown simultaneously with the $F_{2}$. In addition the physiological action of the 


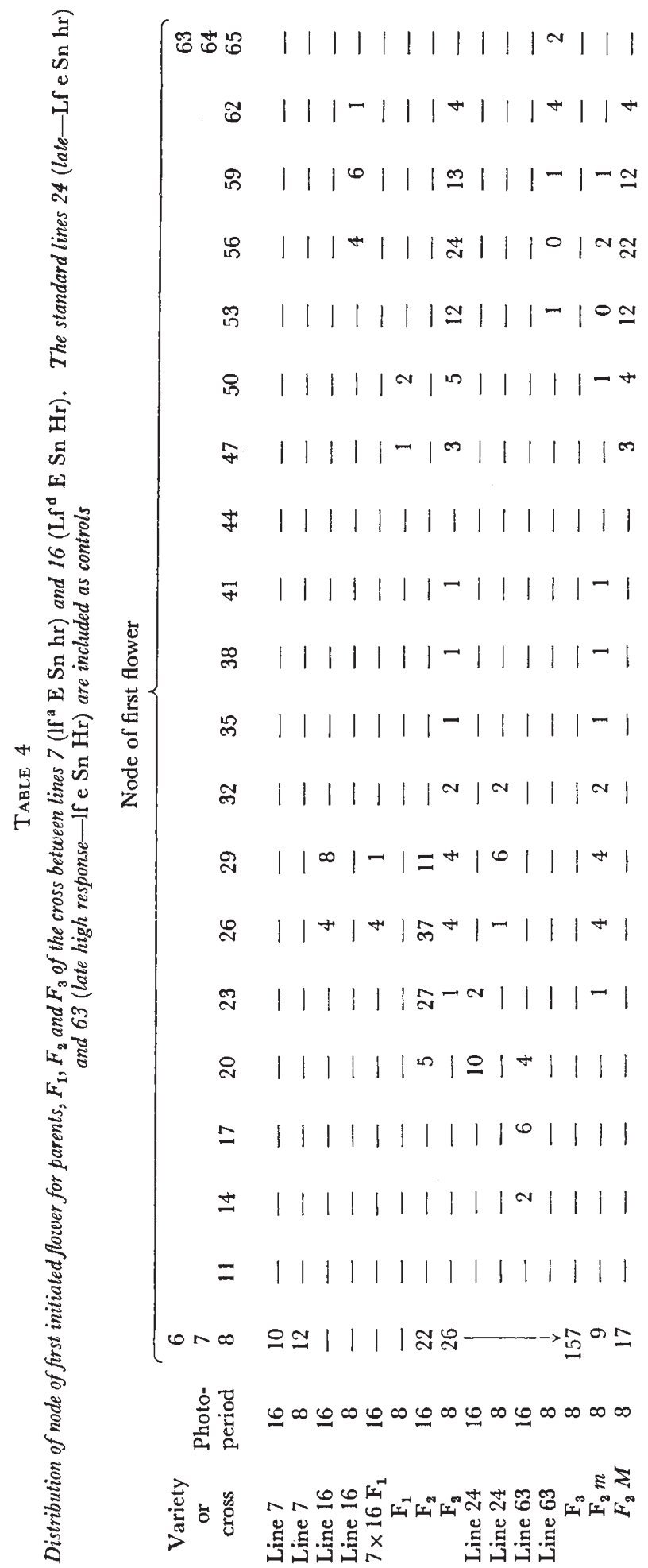


flowering genes was investigated by making reciprocal grafts between lines 7, 22, 24 and 16 using the technique described by Murfet (1971c). Data are taken from main shoots only and laterals were regularly excised. Nodes are counted from the first scale leaf as node 1. Flowering node refers to the first node at which a flower bud was initiated irrespective of subsequent development. Since all early segregates in these crosses were of an EI or VEI nature, separation into phenotypic classes can be made without reference to flowering time. The seed marbling gene $M$ is sometimes obscured in $a$ plants but it was recognisable in crosses $7 \times 16$ and $24 \times 16$ by a distinct "ghost" marbling. The gene for long internodes (Le) contributed by line 16 leads to some handling difficulties in the controlled

\section{TABLE 5}

Segregation and linkage data for the flowering loci $\mathrm{Lf}$ and $\mathrm{Hr}$ and marker genes $\mathrm{A}$ and $\mathrm{M}$. All crosses are in coupling.

\begin{tabular}{|c|c|c|c|c|c|c|c|c|c|c|c|}
\hline \multirow[b]{2}{*}{ Cross } & \multirow{2}{*}{$\begin{array}{l}\text { Photo- } \\
\text { period }\end{array}$} & \multirow{2}{*}{\multicolumn{4}{|c|}{$\begin{array}{c}\text { Phenotype } \\
\text { Observed numbers }\end{array}$}} & \multirow[b]{2}{*}{ Total } & \multicolumn{3}{|c|}{ Chi-squared } & \multirow[b]{2}{*}{$\mathrm{CrO} \%$} & \multirow[b]{2}{*}{ S.E. } \\
\hline & & & & & & & Seg. 1 & Seg. 2 & Joint & & \\
\hline $7 \times 60$ & 8 & $\begin{array}{l}A \text { lf } \\
42\end{array}$ & $\begin{array}{r}A l^{a} \\
4\end{array}$ & $\operatorname{alf}_{4}$ & $\begin{array}{l}a \text { lf } a \\
15\end{array}$ & 65 & $0 \cdot 6$ & $0 \cdot 6$ & $40 \cdot 0 * * *$ & $12 \cdot 4$ & $4 \cdot 4$ \\
\hline $7 \times 2$ & 18 & $\begin{array}{rl}A & L f \\
59\end{array}$ & $\begin{array}{r}A l f^{a} \\
4\end{array}$ & $a \underset{2}{L}$ & $\begin{array}{r}a \text { lf } \\
14\end{array}$ & 79 & $1 \cdot 0$ & $0 \cdot 2$ & $39 \cdot 2 * * *$ & $8 \cdot 0$ & $3 \cdot 2$ \\
\hline $7 \times 2$ & 8 & 129 & 10 & 5 & 28 & 172 & $3 \cdot 1$ & $0 \cdot 8$ & $72 \cdot 9 * * *$ & $9 \cdot 4$ & $2 \cdot 4$ \\
\hline $7 \times 16$ & 16 & $\begin{array}{rl}A & L f^{d} \\
& 70\end{array}$ & $A l_{5}^{a}$ & $a \underset{9}{L}$ & $\begin{array}{l}a l^{a} \\
17\end{array}$ & 101 & $0 \cdot 1$ & $0 \cdot 6$ & $36 \cdot 0 * * *$ & $14 \cdot 8$ & 3.9 \\
\hline $7 \times 16$ & 8 & 71 & 7 & 4 & 19 & 101 & 0.3 & $0 \cdot 1$ & $48 \cdot 1 * * *$ & $11 \cdot 3$ & $3 \cdot 4$ \\
\hline $16 \times 24 \dagger$ & 18 & $\begin{array}{l}A \underset{94}{L} f^{a} \\
\quad 94\end{array}$ & $\begin{aligned} A L f \\
22\end{aligned}$ & $a \underset{7}{L}$ & $a \stackrel{L f}{26}$ & 149 & 0.7 & $4 \cdot 1 *$ & $42 \cdot 1 * * *$ & $18 \cdot 4$ & $3 \cdot 6$ \\
\hline $7 \times 16$ & 8 & $\begin{array}{c}M H r \\
57\end{array}$ & $\begin{array}{r}M h r \\
0\end{array}$ & $\begin{array}{c}m \mathrm{Hr} \\
4\end{array}$ & $\begin{array}{r}m h r \\
14\end{array}$ & 75 & $0 \cdot 1$ & $1 \cdot 6$ & $43 \cdot 3 * * *$ & $5 \cdot 8$ & $2 \cdot 8$ \\
\hline
\end{tabular}

$\dagger$ Continuous $F_{2}$ arbitrarily cut at nodes 18/19; genotypes unsubstantiated.

photoperiod facility, particularly in short days where the delayed flowering may result in plants over 6 metres tall. Height difficulties were avoided in cross $7 \times 16$ by growing only le segregates and switching the short day plants to long days after the elapse of three months. Single, double and triple asterisks against $\chi^{2}$ and other statistics indicate probabilities less than $0.05,0.01$ and 0.001 respectively. Other experimental details are given in previous papers.

\section{Results}

(i) The allele If a

Flowering node data for cross $7 \times 60$ are given in table 1 . The parental varieties flower on average little more than three nodes apart and the $F_{2}$ is apparently continuous. Nevertheless the flowering node distribution is 
strongly bimodal and the full $F_{3}$ analysis shows conclusively that this is a distinct monohybrid segregation determined by alleles of the major flowering gene $L f$. Referring to the region 6-8 as very early and 9-15 as early the $\mathrm{F}_{\mathbf{1}}$ classifies early and the $F_{2}$ segregates into 19 very early and 46 early plants which fits closely a $1: 3$ ratio $\left(\chi_{1}^{2}=0 \cdot 62\right)$. The 19 very early $F_{2}$ plants all bred true in $F_{3}$. (Note one of the 226 offspring flowered at 9.) Of the early $F_{2}$ plants 10 bred true and the remaining 36 gave rise to both very early and early segregates in the proportion of $113 / 317$, numbers which are in good accord with a $1: 3$ ratio $\left(\chi_{1}^{2}=0 \cdot 37\right)$. The $F_{2}$ could therefore be partitioned into 19 recessive, 36 heterozygous and 10 dominant plants which fits a $1: 2: 1$ ratio $\left(\chi_{2}^{2}=3 \cdot 25\right)$. As a further check on the sharpness of the discontinuity between nodes 8 and 9 a larger $F_{2}$ was grown. The $F_{2}$ plants flowering at node 8 always bred true (17 progenies checked), whereas $\mathrm{F}_{2}$ plants flowering at node 9 invariably segregated both very early and early plants (13 progenies checked). Many hundreds of plants of the parental varieties have also been grown; line 7 never flowered later than node 8 and line 60 never earlier than node 9 . It is apparent that development is strongly canalised in the region of nodes 8 and 9 and that the transition across this zone requires a change in major gene state, at least with the type of genetic background present in cross $7 \times 60$.

The flowering genotype of line 7 may be deduced as follows, bearing in mind that L and LHR segregates are likely to flower above nodes 17 and $40-45$ respectively under the short day conditions used for crosses $7 \times 60$ and $7 \times 2$ (the standard lines 24 [L] and 63 [LHR] occur in table 4). The absence of $\mathrm{L}$ plants in cross $7 \times 60$ (lf $E S n h r$ ) at once shows that line 7 carries $E$ (genotype lf $e S n h r$ is $L$ ) and a recessive form of $L f$ (genotype Lf $E S n h r$ is L). In addition, line 7 must carry $S n$ since line 53 (lf e $S n h r$ ) was obtained from cross $7 \times 22(s n)$ and $h r$ since no LHR plants (genotype Lf E Sn Hr is LHR) appeared in cross 2 ( LfE Sn hr) $\times 7$ (table 2). Assumption of a multiple allele at the $L f$ locus recessive to allele $l f$ will explain both the monohybrid segregation for flowering node in cross $7 \times 60$ and the lack of independence between this segregation and segregation for the anthocyanin gene $A$. The cross-over value of 12 per cent (table 5 ) is characteristic of the linkage between the $A$ and $L f$ loci. Using symbol $l f a$ to represent the allele for very early flowering, the genotype of line 7 may be written as $l f^{a} E S n h r$. Additional supporting evidence comes from cross $7 \times 2$ ( Lf $E S n h r$ ) where a discrete monohybrid segregation occurs for flowering node (e.g. the long day data in table 2 ) and a strong linkage is again apparent between the flowering locus and the $A$ locus (table 5).

\section{(ii) The allele $\mathrm{Lf}^{\mathrm{d}}$}

Lines 24 and 16 are the standard lines for the L and VL classes respectively. The lines themselves flower quite separately in long days but their $F_{1}$ is somewhat intermediate in flowering node and the $F_{2}$ is continuous and essentially unimodal (table 3 ). The cross data therefore require rejection of class VL since the flowering difference in long days is not a suitable basis for distinguishing a discrete class. The cardinal property of line 16 is a very high response to photoperiod (table 4) which places it in class LHR. The continuous $\mathrm{F}_{2}$ in cross $24(L f e S n ~ h r a ~ m) \times 16(A M)$ shows little indication of major gene segregation. However, if the flowering node 
distribution is partitioned according to the pigmentation classes $A M, A m$, $a M$ and $a m$, it is apparent that most of the white flowered $\mathrm{F}_{2}$ plants $(a)$ correspond to line 24 whereas most of the purple flowered plants $(A)$ correspond with the $\mathrm{F}_{1}$ or line 16 . If the $\mathrm{F}_{2}$ is arbitrarily cut between nodes 18 and 19 , a $2 \times 2$ contingency analysis shows that the flowering node distribution is not independent of segregation at the $A$ locus (table 5, $\left.\chi_{1}^{2}=42 \cdot 1^{* * *}\right)$. This effect is revealed in another way by the significant difference between the mean flowering node of the $a$ and $A$ segregates (see foot of table 3 ). These results can be explained by line 16 possessing a very late allele at the $L f$ locus, for which symbol $L f^{d}$ is proposed. Further supporting evidence is given in subsequent sections.

A full genotype of $L f^{d} E S n H r$ is tentatively suggested for line 16 on the basis of the evidence below. With $L f^{d}$ epistatic to $E$, the combination $S n H r$ will account for the very large response to photoperiod in this line. The short day $\mathrm{F}_{2}$ of cross $7 \times 16$ segregates clearly into $26 \mathrm{VEI}, 14 \mathrm{~L}$ and $61 \mathrm{LHR}$ plants (table 4 ). These numbers are in excellent agreement with the expected $4: 3: 9$ ratio $\left(\chi_{2}^{2}=1 \cdot 62\right)$ if the two recombinant genotypes $l f^{a} E S n H r$ and $L f^{d} E S n h r$ classify VEI and L respectively. The segregation VEI/L + LHR represents the $l f^{a} / L f^{d}$ pair of alleles and the characteristic linkage is again observed with the $A$ locus (table 5 ). The segregation L/LHR represents the $h r / H r$ pair of alleles and the tight linkage with the $M$ locus (tables 4 and 5) is consistent with the reported linkage of these loci (Murfet, 1973a). The $M H r$ linkage is also visible in cross $24 \times 16$ (table 3 ), where the $A M$ segregates are significantly later than the $A m$ segregates $\left(t_{114}=4 \cdot 67 * * *\right)$. This difference indicates a significant interaction between the $L f^{d}$ allele and the combination $\mathrm{Sn} \mathrm{Hr}$ under long days which in turn supports the view that lines 16 and 24 carry distinctly different $L f$ alleles since no such interaction is visible in the white flowered segregates (compare classes $a M$ and $a m$ in table 3). Finally, the presence of $E$ in line 16 is indicated since preliminary studies (Murfet, unpublished) suggest that plants of genotype $l^{a}$ e $S n h r$ are likely to flower in the gap between the VEI and L segregates of cross $7 \times 16$ (table 4 ).

\section{(iii) Dominance relationships of $\mathrm{lf}$ a, $\mathrm{lf}, \mathrm{Lf}$ and $\mathrm{Lf} \mathrm{d}$}

A dominance order of $L f^{d}>L f>l f>l f^{a}$ is shown and some evidence obtained on the degree of dominance, which is seen to vary with the environment and genetic background in some cases. The degree of dominance of lf over $l f^{a}$ is 0.69 calculated from the genotyped $\mathrm{F}_{2}$ of cross $7 \times 60$ (table 1 ). The environment is probably of little consequence here since the flowering node of these genotypes $\left(l f / l^{a} E S n h r\right)$ is particularly stable. On the other hand, the degree of dominance of $L f$ over lf $^{a}$ on background $E S h h r$ is markedly influenced by the environment in cross $7 \times 2$ (table 2). The long day $\mathrm{F}_{2}$ was not genotyped but $L f$ is obviously showing a high degree of dominance. In contrast dominance is a low 0.06 in short days as estimated from the sample of $F_{2}$ plants genotyped by growing $F_{3}$. The flowering node distribution has broken up in short days to form three separate groups; very early, intermediate and late. $F_{3}$ samples show that the very early group consists exclusively of homozygous $l^{a}{ }^{a} f^{a}$ plants whereas the intermediate group is largely made up of heterogyzotes and the late group largely of homozygous $L f L f$ plants. The heterozygotes have in general 
failed to respond to photoperiod. These results for cross $7 \times 2$ and alleles $L f \mid l f^{a}$ contrast sharply with those for cross $7 \times 16$ (table 4 ), where the $L f^{d} l f^{a}$ heterozygotes responded to photoperiod, never flowered earlier than node 19 and where dominance of $L f^{d}$ over $l f^{a}$ is obviously high in either long or short days and with or without $\mathrm{Hr}$. Lack of data on $\mathrm{F}_{2}$ genotypes in cross $24 \times 16$ (table 3 ) again prevents precise calculation but dominance of $L f^{d}$ over $L f$ appears to be fairly low under these circumstances.

(iv) Quantitative systems

Fig. 1 contains some very definite evidence of polygenic influence in cross $7 \times 60$. The heterozygous $F_{2}$ plants (lf lfa $E S n h r$ ) have been taken and the mean flowering node of the VEI and EI segregates in each $F_{3}$

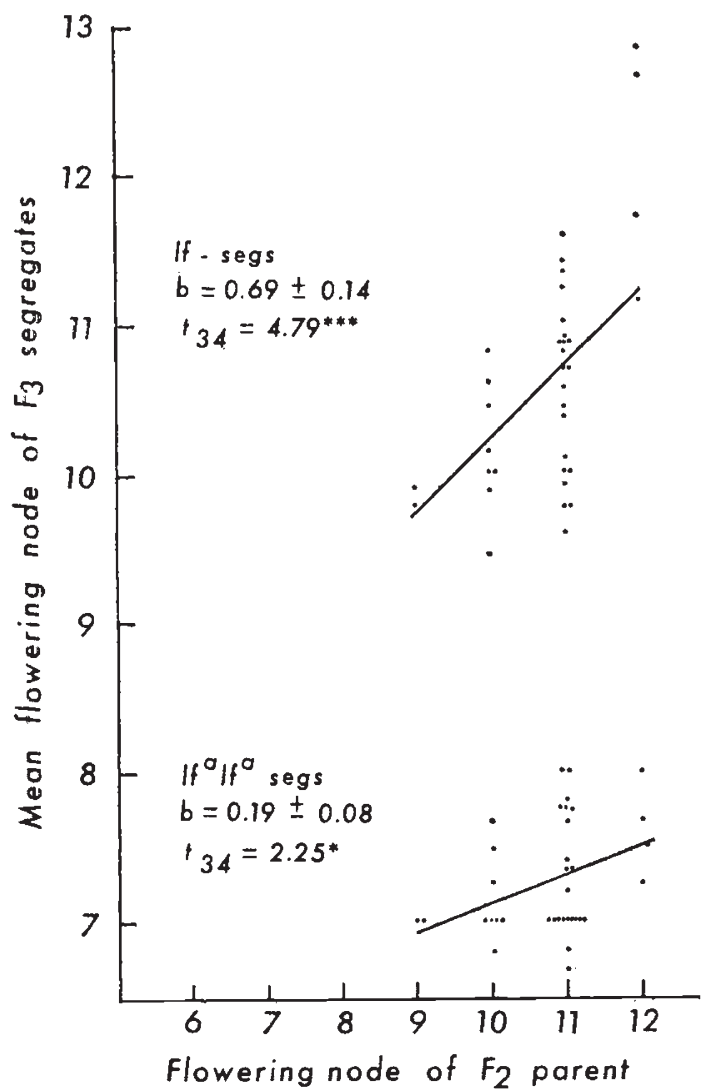

FIG. 1.-Regression of mean flowering node for early and very-early segregates in $F_{3}$ families from heterozygous $F_{2}$ plants in cross $7 \times 60$ plotted against the flowering node of the $\mathrm{F}_{2}$ parent.

progeny plotted separately against the flowering node of the $F_{2}$ parent. It is clear that the node at which flowering occurs within the EI region is highly heritable and that the quantitative genes are capable of influencing flowering by as much as 1.5 nodes, which is approximately half as large as the effect of the major gene $l f$ itself. The same genes are also observed to be having an effect in the VEI region but the size of the effect is diminished. 


\section{(v) Pleiotropy}

Cross $7 \times 2$ is of the form le La cry $\times$ le la Cry with regard to genes controlling internode length. With an le background the presence of either $L a$ or Cry results in a dwarf phenotype whereas the recessive genotype le la cry ${ }^{8}$ results in very long internodes and a phenotype known as "slender". Approximately one-sixteenth of the $\mathrm{F}_{2}$ were slender and a significant flowerdelaying action by this combination of length genes was already apparent (table 6). Larger numbers of slenders appeared in some $F_{3}$ families and this pleiotropic action was confirmed. Perhaps the most striking feature was the near absence of slender plants in the intermediate region (nodes 12-16; see the lower portion of table 2). This suggests that slender has acted as a dominance modifier increasing the degree of dominance of $L f$ over $l f^{a}$ in short days from near zero to a high value. This delaying action is consistent with a previous report (Murfet, 1971b) that slender increases the frequency of vegetative reversion in EI plants.

\section{(vi) The physiological action of the lf alleles}

The results of reciprocal grafts between lines 7, 22, 24 and 16 are given in table 7. The node of first flower in line 7 scions is little influenced by grafting which is not surprising since these $l f^{a}$ apices initiate flower primordia soon after, if not before, germination. (Approximately 6 nodes are already present in pea embryos.) The flowering of line 7 shoots was also very stable and only one case of vegetative reversion occurred in 50 grafts. Johnston (unpublished) likewise found that flowering of line 7 is not delayed to any extent by cotyledon removal. The behaviour of lfa $E S n h r$ shoots is

TABle 6

Pleiotropic effect of the length genes on node of first flower in cross $7 \times 2$ in an 8-hour photoperiod

$\begin{array}{ccccc}\text { Generation } & \text { Background } & \overbrace{\text { Dwarfs }} & \text { Slenders } & \text { Significance } \\ \mathbf{F}_{\mathbf{2}} & L f-E \text { Flowering node } & 17.9 & 22.0 & \mathrm{P}<0.01 \\ \mathrm{~F}_{3} & L f-E S n h r & 19.9 & 23.8 & \mathrm{P}<0.01 \\ \mathrm{~F}_{3} & L f L f E S n h r & 25.2 & 26.7 & \mathrm{P}<0.05\end{array}$

therefore distinctly different from that of lf $E S n h r$ shoots where cotyledon removal or grafting to line 24 can cause a delay of seven to eight nodes (Murfet, 1971c, 1973b). However, these two genotypes perform in a similar manner when used as stocks.

Line 22 scions were unfortunately on the point of flowering at the time of grafting. However, the delaying action of the $S n$ stocks often caused a short period of vegetative reversion above the first flowering node. The node at which stable flowering commenced is therefore used as a statistic for these scions. The problem was compounded in the case of line 24 stocks as these were the slowest to germinate, which may explain why graft $22 / 24$ does not show the three-node delay reported for comparable grafts Massey/ Greenfeast, 59/24 and 58/24 (Paton, 1969; Murfet, 1971c). Stocks 7 and 16 have exerted a significant and approximately equal delaying action on scion 22 which contrasts with the wide difference in flowering node of these stocks grown as intact plants. Their behaviour as stocks for line 24 scions 
$(L f)$ is again fairly similar and line 7 , in spite of its very early flowering, has failed to elicit the striking promotion of flowering achieved by the recessive $s n$ stock line 22 . However, even line 22 proved incapable of inducing early flowering in line 16 scions. This resistance to induction appears to be conferred by $L f^{d}$, since Reid (unpublished) has shown that If $e \mathrm{Sn} \mathrm{Hr}$ scions will flower at an early node in short days if grafted to $s n$ stocks, but data on scion $L f^{d}$ e $S n h r$ would be useful here.

TABLE 7

Node of first initiated flower for reciprocal grafts between lines 7, 22, 24 and 16 performed on days 5 and 6 . Photoperiod 9 hours

\begin{tabular}{|c|c|c|c|c|c|c|c|c|c|c|c|c|}
\hline \multirow[b]{3}{*}{ Stock } & \multicolumn{12}{|c|}{ Scion } \\
\hline & \multicolumn{3}{|c|}{7} & \multicolumn{3}{|c|}{$22^{*}$} & \multicolumn{3}{|c|}{24} & \multicolumn{3}{|c|}{$16 \dagger$} \\
\hline & $\bar{x}$ & S.E. & $n$ & $\bar{x}$ & S.E. & $n$ & $\bar{x}$ & S.E. & $n$ & $\bar{x}$ & S.E. & $n$ \\
\hline 7 & $7 \cdot 1$ & $0 \cdot 1$ & 14 & $11 \cdot 5$ & 0.3 & 13 & $22 \cdot 9$ & $0 \cdot 3$ & 12 & $47 \cdot 7$ & $1 \cdot 6$ & 7 \\
\hline 22 & $6 \cdot 5$ & $0 \cdot 1$ & 15 & $9 \cdot 9$ & $0 \cdot 2$ & 11 & $12 \cdot 8$ & $0 \cdot 3$ & 15 & $47 \cdot 3$ & $1 \cdot 3$ & 12 \\
\hline 24 & $7 \cdot 3$ & 0.2 & 12 & $10 \cdot 6$ & 0.4 & 14 & $24 \cdot 9$ & $0 \cdot 2$ & 13 & $49 \cdot 3$ & 1.6 & 9 \\
\hline 16 & $7 \cdot 0$ & 0.2 & 9 & $11 \cdot 6$ & $0 \cdot 8$ & 10 & $25 \cdot 4$ & 0.5 & 8 & $48 \cdot 0$ & $2 \cdot 4$ & 6 \\
\hline Ungrafted & $6 \cdot 7$ & 0.1 & 15 & $9 \cdot 4$ & 0.1 & 16 & $23 \cdot 8$ & $0 \cdot 3$ & 16 & $55 \cdot 4$ & $0 \cdot 6$ & 12 \\
\hline Genotype & $l f$ & $E n$ & & & e sn & & & $S n h r$ & & $L f^{d}$ & $E S n t$ & \\
\hline
\end{tabular}

* The node at which stable flowering commenced is used since the first flower primordium was already determined in some scions at the time of grafting but vegetative reversion often followed.

$\dagger$ None of the line 16 shoots had initiated flowers at the time of transfer to long days (day 98 ).

In conclusion, these results with alleles $l f^{a}, l f, L f$ and $L f^{d}$ are consistent with the previous proposal (Murfet, 1971c), based on alleles $l f$ and $L f$ only, that the $l f$ locus operates in the shoot and not the cotyledons and is possibly concerned with sensitivity of the apex to the balance of flowering hormones. They also support the proposal that $S n$ controls the formation of a grafttransmissible inhibitor in the cotyledons and shoot. The earlier flowering of graft $22 / 24$ relative to $22 / 7$ and $22 / 16$ does not support the proposal that $E$ reduces inhibitor production in $S n$ cotyledons but this may be an aberrant result due to the maturity of the line 22 scions at the time of grafting to line 24 .

\section{Discussion}

Plants carrying genes $E, S n$ and $H r$ may have anything from five to over 100 vegetative nodes depending on the environment, the polygenic background and the genotype at the $L f$ locus. However, no circumstances are presently known to me, either genetic or environmental, which will cause $L f$ plants to flower before node 11 or $l f$ plants before node 8 whereas $l f^{a}$ plants flower as early as node 5 . The evidence therefore points to the $L f$ series having a basic role in determining the minimum length of the vegetative period.

Two multiple allelic systems concerned with flowering have previously been proposed in Pisum. Wellensiek (1961, 1964, 1969, 1972a, b) has 
reported three alleles $\mathcal{N}_{0}{ }^{h}, \mathcal{N}_{0}{ }^{m}$ and no conditioning flowering at a high, medium and low node respectively. $\mathcal{N}_{0}{ }^{h}$ shows no linkage with $A$ but weak linkage with $F a$ which would place it in group IV. The no series therefore appears unrelated to the present case. Pellew (1940) provisionally represented as alleles for the first time genes $L, l_{1}$ and $l_{2}$, renamed $L i$ by Blixt (1969), determining flowering at the 18th, 15th and 9th nodes respectively. From Pellew's brief remarks it seems quite likely that she was working with the $l f$ locus and possibly alleles $L f^{d}, L f$ and $l f$. The symbol $l f$ (White, 1917) has priority.

Very early flowering peas have been investigated by a number of workers. Lamprecht (1956) proposed two genes $i b$ and $i b a$ determining inflorentia basalis with the earliest plants having as little as two sterile nodes. However, the flowering node of these forms may not be any earlier than the earliest $l f^{a}$ segregates (four sterile nodes) if the present scoring techniques are employed. For example, Lamprecht reported difficulty recognising the lowest nodes, which may not have been counted, and he certainly scored laterals, which often have a flowering node lower than the main shoot. No linkage data are available for $i b$ and $i b a$ but it is of interest that the Acacia line was an ancestor of Lamprecht's cross and the $l f^{a}$ allele may possibly have contributed to the very early flowering of some segregates. Recessive mutants 46 and pra with a flowering node similar to $\mathrm{lf}^{a}$ plants were obtained by Gottschalk (1960) and Monti and Scarascia Mugnozza (1967, 1970) respectively. Mutant pra also shows linkage with $A$ but the figure of 33 per cent is somewhat higher than the values reported here for $l f^{a}$.

The number of major loci concerned with flowering may not be as large as the multiplicity of gene symbols suggests. It would be desirable to draw together the body of genetic information on flowering and attempt resolution of the question of gene relationships by crossing. Such a programme would be facilitated if we had as reference points pure lines designated as types for proposed genes. Lines $65 \mathrm{E}, 59,53$ and 64 are therefore named as type lines for the dominants $L f, E, S n$ and $H r$ respectively; line 58 covers the recessives $l f, e, s n$ and $h r$; line $7 l f^{a}$ and line $16 L f^{d}$. Line 60 (lf $E S n h r$ ) is also useful as a test line.

Testing of the relationships between the flowering genes is rendered difficult by the non-availability of some reference material, the frequent need for controlled environments and by the complex gene interactions. For example, the phenotypic similarity of two parents and their offspring is not sufficient proof that the parents are genetically identical; e.g., lf $E s n h r \times l f e s n h r$ or $L f e S n h r \times l f e S n h r$. It is best to attempt positive identification of the genetic complement by crossing to several key lines. Another problem concerns the relationship between the results of Mendelian analyses and biometrical analyses like those of Snoad and Arthur (1973a, b). These workers have assumed that genes $L f, E, S n$ and $H r$ are not of consequence in long days but there is evidence to the contrary. The present results show that the $I f$ locus can determine a qualitative difference under long days (tables 2 and 4) and the effect of $\mathrm{Hr}$ is quantitative in cross $24 \times 16$ (table 3 ) but detectable with the aid of a tightly linked marker, $M$. The $S n$ gene is certainly active and effective in buried cotyledons even if the shoot is in continuous light (Murfet and Reid, 1974), and cross $64 \times 53$ provides an example of a very obvious $S n$ segregation under a 24-hour photoperiod (Murfet, 1973a, table 1, row 25). By this result the modifier 
$E$ also becomes of significance and cross $60 \times 53$ provides an example of an obvious $E$ segregation in long days (Murfet, 1975). Although the major genes may not be identifiable per se in the field they would be expected in many circumstances to exert at least a quantitative influence.

Acknowledgments.-I thank Drs S. Blixt and G. A. Marx for helpful comments, Mrs K. Gourlay and Mr P. J. Dalton for technical assistance and the Australian Research Grants Committee for financial support.

\section{REFERENCES}

Barber, H. N. 1959. Physiological genetics of Pisum. II. The genetics of photoperiodism and vernalisation. Heredity, 13, 33-60.

BLIxт, s. 1969. Gene list with citations. Pisum Newsl., 1, 23-60.

CLAY, s. 1935. Notes on the inheritance of quantitative characters in a cross between two varieties of garden pea (P. sativum). F. Pomol. and Hort. Sci., 13, 149-189.

GoTrSCHALK, W. 1960. UUber züchterisch verwendbare strahleninduzierte Mutanten von Pisum sativum. Züchter, 30, 32-42.

LAMPRECht, н. 1956. Ein Pisum-Typ mit grundständigen Infloreszenzen. Agri Hort. Genet., $14,195-202$.

MARX, G. A. 1968. Influence of genotype and environment on senescence in peas Pisum sativum L. BioScience, 18, 505-506.

marx, G. A. 1969. Some photo-dependent responses in Pisum. I. Physiological behaviour. Crop Sci., 9, 273-276.

MONTI, L. M., AND SCARASCIA MUGNOZZA, G. T. 1967. Mutazioni per precocita e ramosita indotte in pisello. Genetica Agraria, 21, 301-312.

MONTI, L. M., AND SCARASCIA MUGNOZZA, G. T. 1970. Impiego di una mutazione per precocita in un programma di incrocio per il miglioramento genetico del pisello da industria. Genetica Agraria, 24, 195-206.

murfet, I. c. 1971a. Flowering in Pisum. Three distinct phenotypic classes determined by the interaction of a dominant early and a dominant late gene. Heredity, 26, 243-257. murfet, I. c. 1971b. Flowering in Pisum. A three-gene system. Heredity, 27, 93-110.

mURFET, I. c. 1971c. Flowering in Pisum. Reciprocal grafts between known genotypes. Aust. F. Biol. Sci., 24, 1089-1101.

mURFET, I. c. 1973a. Flowering in Pisum. $\mathrm{Hr}$, a gene for high response to photoperiod. Heredity, 31, 157-164.

MURFET, I. C. 1973b. Flowering in Pisum. The effect of cotyledon removal on genotypes If $E S_{n}$ hr and lf $e$ Sn hr. Aust. F. Biol. Sci., 26, 669-673.

MURFET, I. c. 1975. An obvious $E$ segregation in long days. Pisum Newsl., 7, 41-42.

MURFET, I. C., AND REID, J. B. 1974. Flowering in Pisum: the influence of photoperiod and vernalising temperatures on the expression of genes $L f$ and $S n$. Z. Pflanzenphysiol., $71,323-331$.

PATON, D. M. 1969. Vernalisation, photoperiodic induction and flower initiation in the late pea cultivar Greenfeast. Aust. F. Biol. Sci., 22, 303-310.

PELlew, C. 1940. Genetical studies on the first reciprocal translocation found in Pisum sativum. 7. Genet., 39, 363-390.

Rowlands, D. G. 1964. Genetic control of flowering in Pisum sativum L. Genetica, 35, 75-94.

SNOAD, B., AND ARTHUR, A. E. 1973a. Genetical studies of quantitative characters in peas.

I. A seven-parent diallel cross of cultivars. Euphytica, 22, 327-337.

SNOAD, B., AND ARTHUR, A. E. 1973b. Genetical studies of quantitative characters in peas. 2. A six-parent diallel cross of cultivars and primitive forms. Euphytica, 22, 510-519.

WATTS, L. E., STEVENSON, E., AND CRAMPTON, M. J. 1970. Inheritance of flowering time in six pea cultivars (Pisum sativum L.). Euphytica, 19, 405-410.

WELLENSIEK, s. J. 1961. Early-flowering neutronic mutants in peas. In: Effects of Ionizing Radiations on Seeds, pp. 321-326. I.A.E.A., Vienna.

WELLENSIEK, s. J. 1964. The origin of early-flowering neutron-induced mutants in peas. Rad. Bot. 5, Suppl., 393-397.

WELLENSIEK, s. J. 1969. The physiological effects of flower forming genes in peas. $Z$. Pfanzenphysiol., 60 , 388-402.

$35 / 1-G$ 
WELlensirk, s. J. 1972a. Multiple alleles for late, medium and early flowering. Pisum Newsl., 4, 59.

wellensiek, s. J. 1972b. The localisation of No. Pisum Newsl., 4, 60 .

wHITE, O. E. 1917. Studies of inheritance in Pisum. II. The present state of knowledge of heredity and variation in peas. Proc. Amer. Phil. Soc., 56, 487-589. 